\title{
The Value of Traditional Chinese Painting Appreciation Course of College and University in the Context of Visual Culture
}

\author{
Ling Kong \\ Painting Department, Academy of Fine Arts, Nanjing Xiaozhuang College, Nanjing, Jiangsu, China \\ 651578651@qq.com
}

Keywords: Visual Culture, Traditional Chinese Painting Appreciation Course, Value

\begin{abstract}
In contemporary times, we are surrounded by images. The visualization of contemporary culture highlights the visual sense of the image, which changes the way of viewing the traditional painting art.Elite art meets mass culture. In this context, traditional Chinese painting appreciation course has encountered an embarrassing situation. How to make traditional Chinese painting effectively spread in contemporary universities? This requires us to reanalyze its contemporary value.
\end{abstract}

\section{视觉文化背景下高校中国传统绘画鉴赏通识课程的价值转向}

\author{
孔悀 \\ 南京晓庄学院，南京，江苏，中国 \\ 651578651@qq.com
}

关键词：视觉文化, 中国传统绘画鉴赏通识课程, 价值转向

摘要: 在当代, 我们被层层叠叠的图像或影像包围着。当代文化的视觉化凸显了图像的可视感, 从而使传统绘画艺术的观看方式有所改变。过去的精英艺术与大众文化汇合，中国传统绘画鉴 赏通识课程在此背景下遇到了现实尬境。如何使得中国传统绘画这一精英艺术在当代高校有效 释放，这就需要我们重新分析其当代价值。

1. 引言

“视觉文化是指文化脱离了以语言为主导的理性主义形态，日益转向以形象、影像为中心的 感性主义的形态。”[1]我们正处于视觉文化时代, 图像由过去的稀缺发展到现当代的爆炸, 我们被层层叠叠的图像或影像包围着。经典绘画作品被大量机械复制, 并流向了社会的各个层 面，过去的精英艺术由此被拉下神坛，与大众文化汇合。随着视觉文化时代 “看” 的方式的改 变, 传统经典作品的鉴赏通识课程遇到了现实㸱境，如何使得中国传统绘画这一精英艺术在当 代高校有效释放，这就需要我们重新分析其当代价值。

\section{2. 中国传统绘画鉴赏途经一一 “看的方式”的改变}

伯格在《看的方式》里写到: “我们今天是以一种前所未有的方式去看过去的艺术品。实 际上，我们是以一种不同的方式来欣赏过去的艺术品。由于照相机的出现，如今是绘画趋近观 赏者，而非观赏者趋近绘画。”这段话点出了视觉文化背景下，艺术品 “看的方式” 有了重大 的调整。这种改变还带来了心理学、价值观上的改变。在高校美术鉴赏通识课程中, 学生与中 国传统绘画之间产生的隔膜是显而易见的，这首先体现在“看的方式”的改变。 


\section{1 中国传统绘画独特的鉴赏途经}

这与中国传统绘画的特殊装裱方式有关。中国传统绘画的装裱形式有卷, 轴, 册等。卷是 横向的, 两侧有细木条; 轴则是坚向的, 底端有圆轴, 这两种在收藏时都可以卷起来存放; 册 就是册页, 是受书籍的卷轴装帧影响的书画装裱形式, 由一张张对折的硬纸板组成, 可以左右 或上下翻阅，十分有利于翻看与收藏。中国书画的装裱形式反映了中国书画的 “收藏” 意识, 中国传统绘画创作、鉴赏与收藏的话语权在于古代文化精英阶层，“收藏” 的意识也显出了对 艺术品的珍视，拉开了大众与艺术品的距离，并且使得对艺术品的鉴赏具有了仪式感。

\section{2 传统鉴赏过程的仪式感}

伯格在《看的方式》中强调: “视觉艺术总是存在于某种收藏形式之中; 最初这种收藏是 神秘的或神圣的。”中国传统绘画分为卷轴、长卷、扇面、册页等，这种装裱方式除了外在的 形式美，更方便于收藏。这种特殊的收藏方式营造了一种鉴赏的仪式感。不同于西方绘画的架 上绘画，它们是挂在墙上，直接、完整地呈现给观者。而中国传统绘画的传统鉴赏方式则是 “流 动” 的, 特别是长卷, 比如《千里江山图》, 纵 51.5 厘米, 横 1191.5 厘米, 接近十二米的长 度，观者一般是边展开鉴赏，边卷起来，所以其鉴赏的目光是移动的，带有了 “游” 的性质， 在画面处理上，画家不但要考虑到全景构图，还要对局部构图细细研磨，因为观者是从局部细 节开始鉴赏，每截取一个片段，都带给人完整的感觉; 每一个局部片段又连成一个完整的、宏 大的整体。又比如《富春山居图》，在历史上曾被烧成两截，还损毁了一部分，现存有浙江省 博物馆的《富春山居图·剩山图》，尺幅:纵 31.8 厘米，横 51.4 厘米; 以及台北故宫博物院的 《富春山居图·无用师卷》，尺幅:纵 33 厘米，横 636.9 厘米。虽有遗憾，但并不影响我们的鉴 赏，每一个局部都是经典，都是完整的 “小世界”，这些 “小世界” 中的 “气脉” 是相通相连 的, 因此观看时的视觉流动不会滞涩。不同于西方经典绘画的科学透视法带给画面的“聚焦感”, 这种 “聚焦感” 带给画面一种闭合的坚固的完整性，它是不易碎的，也不能分解。中国传统绘 画却没有 “聚焦感”，它是一种 “延绵流动” 的视觉方式，视觉流动到哪，哪就是焦点。这种 “流” 的 “看的方式” 映射着中国古典的哲学观, 它的空间不是闭塞, 而是开放的, 无始无尽, 循环反复, 是生命的流动。卷轴的鉴赏方式也是从画面逐渐展开开始, 从打开画面的那刻起就 进入了鉴赏过程, 那种流动的主观 “凝视” 所获得的审美愉悦随着画面的完全展开达到顶峰。 卷轴展开时的审美体验也是一种审美创造, 是动态的审美过程。扇面与册页的鉴赏亦是另一种 形式的 “观看” ——把玩。扇面、册页的尺寸正好可以供这些藏家拿在手里反复欣赏品鉴。

在图像稀缺的过去, 这些名画只是少数人的珍爱物, 非拥有者们为了能够一睹名画风采, 可谓费尽心血。当他们来到名画前的一刻, 激动的心情还得抑制住, 漱手焚香, 怀着敬畏的心 情在案头缓缓展开画卷。鉴赏过程的仪式感会先抑制住将要迸发的情感, 并在后面的释放中在 心理上扩大审美期待度, 从而达到深层次的审美愉悦。

\section{3 视觉文化时代 “看的方式” 的转变}

在视觉文化时代，图像从传统社会中的稀缺资源发展到当代却 “爆炸”成无处不在，可以 说我们正处于被图像包围的时代。传统经典的艺术品被拉下神坛，就如伯格所说：“现代复制 方式所做的事情就是摧毁艺术的权威性, 解放它一一或更准确地说, 就是将其所复制的图像与 其任何收藏分离开来。因为这是在历史上首次使艺术形象成为短暂的、无处不在、非本质性的、 可接近的、无价值的和不受限制的了。”艺术品的机械复制品铺天盖地。比如达芬奇的《蒙娜 丽莎》, 原来只是私人藏品, 是少数人观赏的艺术品; 后来成为国家或社会的收藏, 放在了卢 浮宫博物馆, 使得观赏人数大幅度扩大; 而在现当代则被广泛地机械复制, 出现在各个角落, 成为全世界都熟悉的艺术图像，撕去了神秘面纱。这种审美的社会深度泛化反而使得慕名前来 观赏真品的游客们在面对真品时却没有了鉴赏的心情, 有的甚至是失望, 觉得还没有其高清复 制图像清晰好看。中国传统绘画的鉴赏亦是如此, 大量的机械复制品泛滥, 不需要去看原作, 就能从印刷品、画册、网络图片、微信平台等媒介获得原作的详细信息, 传统的鉴赏仪式感已 
消失，原来的主观凝视转向为被动观看，显出了观看者的被动性，有时甚至是 “被迫观看”, 经常与图像不期而遇。当人们能够频繁接触到艺术品的复制品后，已对真品麻木，甚至厌倦。 “当美的事物到处泛滥时, 当人们沉浸在舒适美观的生活环境之中时, 便不可避免地出现一种 “麻痹化” 和 '冷漠'。”[2]

\section{3. 中国传统绘画鉴赏通识课程的现实䛈境}

中国传统绘画鉴赏课是高校的通识课程。“通识教育的核心问题是自由而文雅的传统之持 续问题”。[3]在高校, 通识课程的设置旨在培养完整、完全、自由的人，学生能够对不同的 学科有所了解, 这也是针对当代高校学科分类过于专业化的弊端而提出的博雅通才的教育理 念。中国传统绘画鉴赏课作为能够宣传中国传统经典文化的课程在高校是十分必要的。但在实 际教学中却遇到了现实尬境。

首先，在大众文化崛起的当代，如何解读精英艺术？在当代，大众文化与精英艺术的对撞 是文化常态。洛文塔尔说过: “在现代文明的机械化进程中, 个体衰落式微, 使得大众文化出 现，取代了民间艺术或 “高雅” 文化。大众文化产品没有一点真正的艺术特色，但在大众文化 的所有媒介中，它具有真正的自我特色：标准化、俗套、保守、虚伪、人为控制的生活消费品”。 精英艺术被消解于大众文化中，高校学生对精英艺术是既 “熟悉” 又 “陌生”，对精英艺术也 是采取一贯式的 “碎片浏览”。基于处于视觉文化时代这个现实，当代美术教育提出了由培养 学生的美术鉴赏能力转向 “视觉识读能力”。““视觉识读能力” 是运用视觉的方式由表及里 地感知、欣赏并解读视觉对象的能力。” [4]其中包括了视觉感受能力、视觉审美能力、视觉 解读能力。其实 “视觉识读” 中的视觉对象更多的是大众文化产品, 旨在培养学生能够处理这 些大量图像资料的能力, 这也就是 “碎片浏览”。然而解读经典绘画作品与这种 “碎片汶览” 的方法是相悖的, “碎片浏览” 导致学生缺少思考, 不能完成 “精读”, 亦不能构建完整体系。 而中国传统绘画的鉴赏需要精微细致地深入完成一个整体的、流动的观看。

其次, 文化理解与审美距离的差异。由于当下的高校学生从小就处于图像爆炸的视觉文化 时代, 他们就是 “读图” 长大的, 因此平常一点的图像根本吸引不了他们的眼球。“博眼球” 成了当下大众文化中非常重要的推广方式，比如，当我们浏览网页时就能经常看到 “惊悚” 的 标题。图像亦是如此, 必须让人 “震惊”。“我们不用观照, 只需代之以轰动、同步、直接和 冲击”。[5]当代图像的观看方式是被动的、当下的 “冲击” ，唯有这样，才能刺激到麻痹的 视觉。与此相反，中国传统绘画的观看方式是主动的、精细的 “流动” ; 另外，中国传统绘画 自身的艺术特色是典雅内敛的，没有逼真的造型、丰富的色彩、宏大的叙事、精妙的写真等吸 引学生眼球的特质，然而其中蕴含的文化信息量巨大，更多包含了 “看不见的”、具有深厚的 民族文化传承的内容，这些都与接受当代文化熏陶的高校学生之间产生了“文化代沟”。

\section{4. 中国传统绘画鉴赏通识课程的当代价值转向}

即便中国传统绘画鉴赏通识课程在当代遭遇了现实尬境, 我们仍然认为这门课的开设是十 分重要且必要的。视觉文化是大势所趋, 我们必须根据现状进行教育调整以适应 “多元文化”, 使得中国传统绘画的审美价值在当代高校能够有效释放。

\section{1 中国传统绘画中的 “日常” ——生态审美}

尼古拉・米尔佐夫在《什么是视觉文化》中指出：“......视觉文化，它不仅是你生活的一 部分，而且就是你的日常生活。”[6]当代视觉文化是大众泛审美化时代，更加趋向于 “日常 生活的审美化”。“日常生活” 是琐碎的，随着科技的发展，大众日益关注 “日常”，这就需 要艺术感知力的培养, 能够去粗存精, “净化” 日常生活。中国传统绘画就是一种对日常生活 的 “净化”。中国传统绘画的题材非常广泛，大致分为山水、花鸟与人物三大门类。其中山水 画与花鸟画更为关注自然，这也是基于中国古代农业社会对自然 “日常” 的天然亲昵，在绘画 图像中捠弃琐碎与粗粝，从画面中延伸出或宏观或精微的世界。另外，中国传统绘画对自然生 
态的关注对当今社会亦是有着重要价值。“某种看不见的视觉暴力, 使得审美越来越远离自然、 质朴和自由。这将会导致一种反向冲动一一回归自然。” [7]中国传统绘画中宁静悠远的自然 境界无疑使其在图像喧器的当代似一股清流。动画短片《美丽的森林》就是选取宋代经典的工 笔花鸟画《红蓼水禽图》、《碧桃图》、《果熟来禽图》等, 通过挖掘中国传统绘画中的生态 观来审视当代社会。这些古画以影像的方式复活了过来，典雅精致的画面获得了意想不到的视 觉效果。

\section{2 中国传统绘画中看不见的 “象”-—图像维度的拓展}

中国传统绘画主要是以 “观物取象” 的方式，“立象以尽意”，所以其中蕴含的世界是无 限深厚与宽广的，追求 “象外之象、景外之景”，对 “看不见的” 的 “象” 尤其觉得 “妙” , 如笪重光所说的 “虚实相生, 无画处皆成妙境”。因此, 对中国传统绘画的鉴赏就要引导学生 能够通过图像的表面体会到内在的 “象”。

“看不见的” 的 “象” 对当代的意义是十分重大的。我们所处的 “图像” 时代就是普遍视 觉化的时代, 可见性是大众关注的观看原则, “从传统的 “看法” 向现代的 “看法” 的转变, 就是推进 “透明”、“照亮”、“启蒙”、“看见’、“去蔽” 等可视化进程。” [8] “可见” 的视觉习惯已经让大众越来越忽视 “看不见的” 内容, 从而削弱了图像的维度。中国传统绘画 中的 “象” 超越了 “像” ，超越 “像” 的那部分 “象” 更是重要的审美对象，有着更为丰富的 内容。因此在艺术鉴赏通识课中加强对 “象” 的审美, 会给学生一个不一样的 “看法” ，拓展 对图像的识读维度。

\section{3 “碎片” 的魔咒}

当代阅读方式发生了剧变，大众获得知识的途径有许多来自于手机、网络等新媒体，这些 新媒体一般是以文字、图像、声音、影像等复合形式跨媒体、跨时空传播，显出了 “碎片化” 的特点。虽然这种阅读方式大大提升了阅读效率，能够在碎片化的时间里获得大量的信息，但 这种 “碎片汶览” 的特点是 “管中窥豹” , 缺乏整体性, 获得的信息是零星松散的。而我们对 艺术的鉴赏必须要有一个整体观念。亚理斯多德就提过 “艺术有机整体观念” : “美与不美, 艺术作品与现实事物, 分别就在于在美的东西和艺术作品里, 原来零散的因素结合成为一体。” 中国传统绘画中亦十分看重 “整体意识” , “ “以整体为美” 既是中国传统美学的审美原则也 是艺术创造原则，更是审美欣赏原则。” [9]中国传统绘画的审美观照是 “游观”，是 “仰观 俯察”，也是对生命的 “内视”。因此，在高校通识课，我们应强化这种 “整体意识”，通过 对中国传统绘画的鉴赏，使学生能够感受到 “天人合一” 的 “象” ，体会对世界整体的把握。

\section{4 中国传统绘画在当代文化产业中的传播与价值利用}

中国传统绘画在当代借由科技媒体有了新的表达方式，也成为文化产业中的一部分。中华 艺术宫的多媒体版《清明上河图》就是一种尝试: 应用现代的科学技术使得这张著名的长卷由 静态景观变为动态景观, 原作长卷的尺寸: 纵 24.8 厘米, 横 528.7 厘米, 这种尺寸正适合拿在 手中近距离展看细细赏鉴; 中华艺术宫多媒体版《清明上河图》的尺寸则是 “震撼” : 纵 6.5 米, 横 128 米, 比原作大了近 30 倍, 观看者不需要趋近图像, 图像凭着巨大的尺寸, 结合了 声光电全效, “扑面而来” , 撞入人的眼球, 这是一种全新的观看方式, 经典的《清明上河图》 借由科技成为 “奇观” ，使得大众熟知，成为中华艺术宫的镇馆之宝，吸引大量的游客来此观 看。在有着多元文化的当代，随着中国国力的增强，民族自信心前所未有地提升，大众也越来 越多地关注传统文化, 有的甚至成为文化产业中的噱头, 比如各类国学班的开设, 从汉服礼仪、 特色课程、文化活动等等形成了完整的文化产业链, 产生了巨大的经济效益。影视文化产业亦 是抓住这样的文化心理，弘扬民族优秀文化的同时，又能获得好的收视率。比如央视在 2017 年度推出的一档大型文博节目《国家宝藏》，央视联合了中国九大博物馆，每一期节目一家博 物馆推出三件国宝, 由明星们作为国宝守护人, 编撰并表演故事, 舞台结合多媒体设计, 多层 次多维度地传播国宝文化，全方位地吸引眼球，获得了收视成功。在《国家宝藏》第一期中推 
出了宋画《千里江山图》，通过电视化的语言讲述其前世今生，再加上 “明星效应”，给观众 留下了深刻的印象，掀起了国宝热，博物馆参观成为游客选择的热门，也带动了一系列的文化 周边产品。基于当代文化产业的需要, 高校的艺术通识教育就得跟上形势, 引导学生能够深层 次地鉴赏中国优秀的传统文化, 将文化产业做好做强做深，做出中国的民族特色来，而不是浮 于表面与形式。

\section{5. 结语}

当代科技的突飞猛进给我们的生活带来了极大的改变，我们享受着科技带来的便利与舒 适, 通过图像了解世界、了解自己, 深深依赖于图像, 渐渐地被图像异化, “我们与图像的关 系与其说是 “役物” 关系，不如说是 “物役” 的关系，是一种被图像所左右的关系。” [10]图 像对生存方式的浸润改变了我们的观看路径, 我们以视觉思维的方式观看世界, “世界被把握 为图像了”，这 “标志着现代之本质”。[11]但细思极恐。在刘慈欣的科幻小说《三体・死神 永生》的结尾部分, 却如寓言: 整个太阳系成为了一张图像, 一切寂灭。图像虽然是我们视觉 的延伸，但其间的维度是大大削弱的，我们需要关注于 “看见的”，但更需要思索 “看不见的”。 中国传统绘画中的 “象” 正是我们艺术教育者们需要引导学生去体会的世界，从而扩大 “看” 的维度，并能从中有效传承优秀的民族文化，这也是艺术通识课的价值所在。

\section{引文注释}

[1]王大根.美术教案设计 $[\mathrm{M}]$.上海：上海人民美术出版社，2000，第 17 页

[2]周宪.视觉文化的转向[M].北京：北京大学出版社，2008，第 137 页

[3] 曾繁仁.美育十五讲[M]. 北京: 北京大学出版社, 2012, 第 221 页

[4]王大根.美术教案设计[M].上海：上海人民美术出版社，2000，第 17 页

[5]（贝尔：《资本主义文化的矛盾》，三联书店 1989 年版，第 159 页。）

[6] [美]尼古拉 - 米尔佐夫著, 王有亮译. 什么是视觉文化 $[\mathrm{J}]$ 文化研究（第三辑），2002，（1）: $1-12$.

[7]周宪.视觉文化的转向[M].北京：北京大学出版社，2008，第 137 页

[8]周宪.视觉文化的转向[M].北京: 北京大学出版社, 2008, 第 46 页

[9]樊美筠.中国传统美学的当代阐释 [M]. 北京: 北京大学出版社, 2006, 第 35 页

[10]周宪.视觉文化的转向 $[M]$. 北京: 北京大学出版社, 2008, 第 60 页

[11]孙周兴编.海德格尔选集[M].上海：上海三联书店，1996，第 899 页

\section{参考文献}

[1] 㚞美笏.中国传统美学的当代阐释[M].北京: 北京大学出版社, 2006 .

[2] 曾繁仁.美育十五讲[M].北京: 北京大学出版社, 2012.

[3] 周宪.视觉文化的转向 $[\mathrm{M}]$.北京: 北京大学出版社, 2008 .

[4] 孙周兴编.海德格尔选集[M].上海: 上海三联书店, 1996.

[5]贡布里希.艺术与错觉 [M].杭州: 浙江摄影出版社, 1987.

[6]本雅明.机械复制时代的艺术作品[M].杭州：浙江摄影出版社， 1993.

[7]周宪.审美现代性批判[M].北京: 商务印书馆, 2005.

[8] 陶东风主编.文化研究精粹读本[M]. 北京: 中国人民大学出版社, 2006.

[9]王大根.美术教学论 [M].上海: 华东师范大学出版社, 2000.

[10][法]让・鲍德里亚.消费社会[M].南京：南京大学出版社, 2001. 